\title{
Nutrition Counselling - From the Traditional Setting to Tele-Counselling
}

\section{Elisabeth Farmer}

FH Gesundheitsberufe OÖ GmbH, Campus Gesundheit am Ordensklinikum Linz, Studiengang Diätologie, Ausbildungszentrum, Linz, Austria

\author{
Keywords \\ Digital nutrition counselling · Counselling training \\ Tele-counselling
}

\begin{abstract}
At the University of Applied Sciences for Health Professions in Linz, Austria, students for the first time completed training for online nutrition counselling. Adjusting to the virtual setting as well as briefing and equipping the training clients was a challenge.
\end{abstract}

After initial scepticism, a percentage of students can now see themselves offering digital counselling sessions in their future lives as nutritionists.

(c) 2020, S. Karger GmbH, Freiburg

\section{Background}

The COVID-19 pandemic is often referred to as the driver of digitalisation. There is hardly any area of daily life that has not been influenced by it. From the beginning, this challenge was successfully met by the University of Applied Sciences for Health Professions, and students were appreciative of the fact that academic activities continued without delay.

While online lectures, exams, and teamwork have become routine by now, in the winter semester 2020 the study programme "Dietetics" faced a new task:

During their 3rd and 4th semesters, students usually train for their later work in hospitals or rehabilitation centres by conducting supervised nutrition counselling sessions. The aim is to phrase dense knowledge as well as complex contexts and processes in an easy-to-understand way to inform and support patients in the best way possible.

As in previous years, these counselling sessions were to take place in person during the winter semester 2020. However, due to the COVID-19 pandemic, the situation changed. At the beginning of the winter semester, students and teachers still hoped that volunteers could be invited to the university for these exercises. However, when it became clear during autumn 2020 that the spread of the SARS-CoV-2 coronavirus would make this impossible, alternatives needed to be found.

What to do? Cancel the counselling exercise for 18 students? Stay on the safe side and train in role-play sessions? Or take the plunge and...

\section{Plan, offer, and conduct tele-counselling sessions}

In retrospect, there was no real alternative to this decision. However, the challenge of putting the idea into practice was enormous at the time. For clients, students, and teachers alike, the digital setting was uncharted territory, and no one had any experience to draw upon.

Since conducting a tele-counselling session requires more preparation than simply switching on two computers and two webcams, the nutrition consultations had to be meticulously planned in advance: 


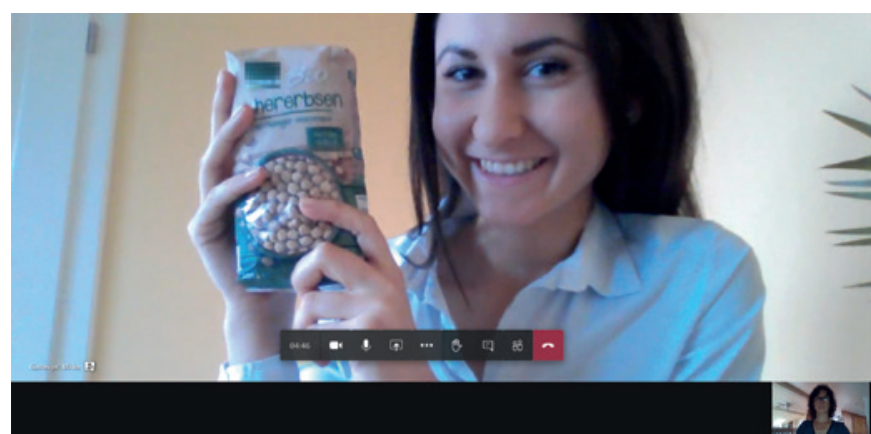

Fig. 1. The student shows a product during the nutritional counselling session.

- What technical equipment is necessary?

- Setting up appointments with clients.

- How can technical support, if needed, be provided for patients who are likely to be at home?

- What tools or visual aids can be prepared or digitised for use during the consultations?

- Preparation and digitisation of counselling documents and transmission to clients.

Once planning was completed, 18 teleconsultations were conducted between January 2021 and April 2021 (Fig. 1, Fig. 2).

\section{Conclusion: Can tele-counselling be an alternative to in- person counselling?}

Although scepticism prevailed in the beginning, it soon became clear that making the effort and 'jumping in at the deep end' were worth it. The online counselling sessions were perceived as rewarding by all involved. For clients, students, and teachers alike, leaving their comfort zone and trying something new and unknown resulted in success - a WIN-WIN-WIN situation, so to speak.

Although the patients, most of whom were 60 years and older, were sceptical at first, feedback showed that after initial uncertainty they quickly became familiar with the situation. They felt well understood and competently advised and were very grateful for this form of nutrition counselling.

It was also noted that geographical independence was perceived as positive. For the first time in most cases, clients in this setting experienced that teleconsultation allowed them to use a medical service without the need to leave their homes (Fig. 3).

Ideally, our "experiment" will have helped to promote willingness to use online health services in the future.

The students involved have no regrets with regards to the amount of work they had to put in during the planning phase. Initial nervousness gave way to the positive feeling of having mastered the first online nutrition counselling with flying colours. One student writes:

"In general, I would have preferred to do the counselling in person with my patient. However, I ended up really liking online counselling. I see this kind of communication as a viable method for the

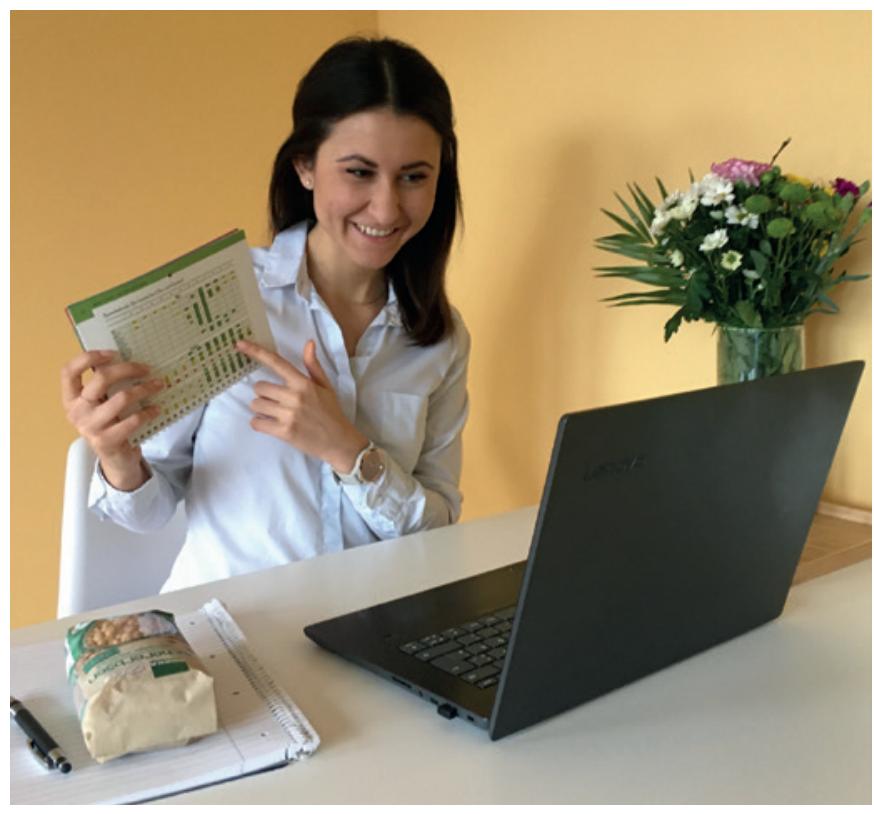

Fig. 2. The student explains the composition of food using a graph.

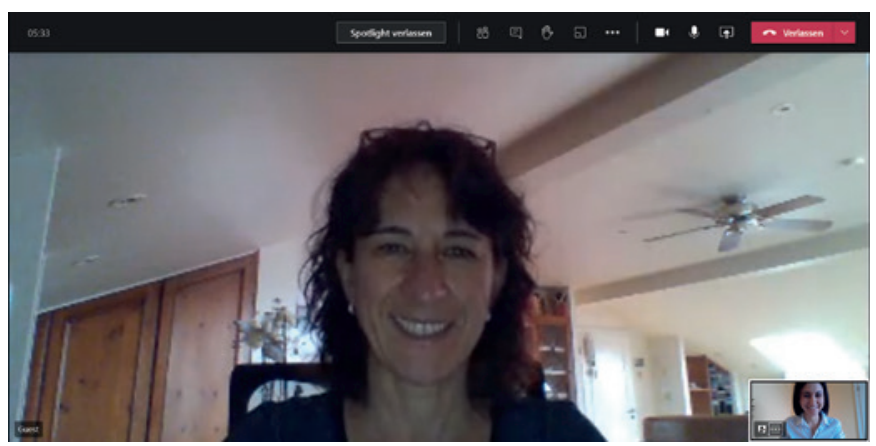

Fig. 3. The client can receive nutrition counselling regardless of location.

future and can very well imagine that I will include online counselling sessions in my future work life." (S.S.)

The students now look forward to their upcoming internships with fresh motivation and are confident that they are well equipped for nutrition consultations - whether in person or online.

The project was important for yet another reason: The organisers of the degree programme are aware of the situation on the job market - vacancies for dieticians are extremely rare. This makes it even more important to prepare students in the best way possible. By implementing the pioneering project "Teleconsultation in Dietetics," an essential contribution was made to train graduates in new aspects of work and improve their job prospects.

Although born out of necessity due to the special circumstances created by COVID-19, this project ultimately resulted in a rewarding experience that broadened the perspectives of everyone involved. 


\section{Disclosure Statement}

The author hereby declares that there are no conflicts of interest with regard to this article.

\section{Literature on digital nutrition counselling}

Arms E: Digitale Ernährungsberatung. Ein Diskussionsbeitrag über Entwicklungen und Trends. Ernährungs Umschau 2020;6:M330-M336.

Götz M: Professionelle digitale Ernährungsberatung. Anforderungen und Einsatzmöglichkeiten verschiedener Formate und Methoden. Ernährungs Umschau 2020; 6:M336-M343.
Keuthage W: Stellenwert der Telemedizin in Pandemiezeiten. Aktuelle Ernährungsmedizin 2020;45:435-438.

Weishaupt E, Jent S, Zbären E, Haas K: Online nutrition counselling on weight loss. Experiences of overweight and obese adults. Ernahrungs Umschau. 2020;67:108-114.

Weishaupt E, Jent S, Zbären E, Haas K: Online-Ernährungsberatung zur Gewichtsreduktion. Erfahrungen von übergewichtigen und adipösen Personen. Ernährungs Umschau 2020;6:108-114. 